\title{
Foreign Language Teaching Relying on Literary Text
}

\author{
Qing Zhu \\ Neijiang Normal University, Neijiang, 641007, China
}

Keywords: Literary text; Foreign language; Teaching

\begin{abstract}
The traditional foreign language teaching is often only concerned with the surface structure of language, and using isolated words or sentences as the center to teach foreign language knowledge. After relying on literacy text teaching, foreign language pays more attention to the context which is focusing on understanding the structure of the literacy text and extending the background knowledge, so as to better improve the learners' English language communicative ability. Based on the overview of the literacy text, this paper conducts analysis for structuralism, reader response, language, literary criticism and other common foreign language teaching methods related to literary text, and has proposed the specific strategy for the application of literary text in foreign language teaching.
\end{abstract}

\section{Introduction}

Foreign language teachers are inevitable to handle literatures. In addition to cultivating the learners' language skills, literary text teaching can also better stimulate their imagination, cultivate students' cultural awareness and critical thinking. Most importantly, literary text teaching applies to learner-centered, interactive and communicative principle of language teaching. Today, however, a large number of foreign language teachers focus on the teaching of language teaching methods, rarely involve the analysis of literary text and reasonable classroom activities design, so that the interests of both teachers and students get lost. Fortunately, there are still all kinds of resources available which are able to improve the effectiveness of literary text teaching. Therefore, the author attempts to analyze the foreign language teaching methods and strategies relying on literary text, and hope to provide effective reference for literary text handling in foreign language teaching.

\section{Overview of literary text}

Literary text, either a novel, may also be an essay, and can be a poem or is a piece of theatrical works, etc., even a complete fragment of them. Literary text not only has meaning of information which other texts must have, it also embodies the creator's aesthetic pursuit. In fact, the foreign language textbook colleges commonly used at present English Extensive Reading Course selects a large number of outstanding literary texts. For example, Ernest Hemingway's novel The Old Man and the Sea, Jack London's novel Love of Life, Helen Keller's essay Three Days to See, Steve Jobs' Speech on the graduation ceremony of Stanford, etc., it can be said that the subject matter covered a wide range of different styles. The above selected literary texts not only provide learners fresh, fun foreign language material, but also allow learners to directly feel the unique charm of Western culture, which help them to further enhance the understanding of language learning.

\section{Commonly used foreign language teaching methods of literacy text}

\section{Structuralism teaching method}

This is a kind of teaching method which has received widespread attention in recent years. This method does not examine the literary text as a single entity, but make it clear how literacy text consider paper and layout to comply with the framework system of all literacy norms This method focuses on the analysis of the overall objectivity of literary text but denies readers' individual response when reading literary texts, which requires students to reach out literary text, and apply it to 
meaningful hierarchy. The teaching method is not concerned about the aesthetic value of literature but rather focuses on set forth the differentiation process and structure of meaning output. Literary text learning should help the personal development of learners, able to enhance their cultural awareness, to develop their skills in language. Although this teaching method uses the correlation between literature and the overall theme structure, making literary text become better understood, but it blindly focus on analyzing the language system, and regards it as the single important determinant factor for interpretation. So, for foreign language teaching, the significance of structuralism teaching method will not seem very impressive. Because foreign language teachers and language learners are lack of knowledge and skills, which lead to them can not better access to literary text, and it would lead to students become futile in the study.

\section{Reader-response teaching method}

This teaching method aims to explore the role of the reader response, and actively support learners can depend on their personal experience, emotional activity when reading literary texts, because every reader has its own unique experience and feelings. The author's idea on literary text may be described by using various differentiated approaches. When thinking and discussing reader response, let the literature would not be in close contact with personal experience mysteriously, so the significance for literature is very great. Language researchers and teachers through activation of learners' desire to learn, so that literature is more easily to understand, in order to better predict the language and theme in literary text, and thus we can improve the motivation to participate of learners. In fact, those above are very important principle for communicative language teaching, to encourage student-centered, improve foreign language learning with process learning. However, reader-response teaching also has some shortcomings, such as the learners own interpretation may significantly deviate from the work itself, which is not conducive to a timely response of the teachers, and even difficult for evaluation of reading materials. Because of the difficulty of the language and unfamiliar with the content, it may hinder learners make meaningful reading. Because of the lack of guidance of language, it may influence students' ability to understand or respond the text. Meanwhile, the cultural foundation of learners may make them unable to openly discuss their response.

\section{Language teaching method}

This method allows the learners' response and experience to literary text become easier. For language learners, this method appears practical and feasible. At the same time, language teaching method also requires to conduct lots of language class teaching activities, which include through brainstorming activate language background knowledge, implementating prediction, rewriting the end of the literary text or roughly outlining the plot, and form their own opinions and conduct a lively discussion. The most important is that the literature is a very good medium for foreign language teaching; the use of interaction and cooperation, it can improve listening, speaking, reading and writing these four skills. At the same time, the role of teachers no longer imposing their own interpretation to learners, but to intervene when necessary. In discussing the needs of language teaching method for learners to learn literature, they should be accepted for language skills and tips, so that they can more easily into the text, train their sensitivity for different register, thus be able to enjoy all kinds of literary texts closely related to their lives. At the same time, this method can meet the needs of learners to foreign language learning. The learners by using foreign language to communicate, can upgrade their language skills thus to foster group discussion skills and thus to truly become active learners. Teachers can actively support and guide learners in learning. Language teaching method is able to inspire students' motivation, it is because it meets the needs of learners to learn language and enjoy literature. Of course, the use of language teaching method is also inadequate, which is lack of the appreciation of literature content.

\section{Literary criticism teaching method}

Literary criticism teaching method absorbs many nutrients from critical language research, educational sociology, feminism and many other theories; though not solely used for literature teaching, but this method has a very important value for language and literature teaching. Because it shows the inherent relationship between language application and social rights, when many people talk about social dimension of language application, often do not concern that many learners' voice in 
foreign language teaching have been ignored. Under many circumstances, foreign language teaching will ignore or rarely involve in how literary text deal with the relationship between ideology and rights in the society. Literary criticism teaching method is very helpful for the learners have critical consciousness on the role of language in generation, maintenance and change of social relations. Another teaching goal of literary criticism method is to actively encourage students to delve into how social factors and political factors form the language which they are learning, so that they can be able to learn more about the social, political and other reasons behind. I think a literary criticism teaching model worth to recommend is conversion generation pedagogy. It is primarily a collaboration and interaction between teachers and students, which will result in the formation of social and political critical awareness of language, but also to acquire language via a strong and meaningful way, so it can better cope with and change the current social reality. Discussion of literary criticism teaching method is very necessary for literature teaching. Learners should recognize how literary text relate to identity, culture, gender, race, class and religion, and learners should ideology assumption implicated in the literary text they read. The teachers who use literary criticism teaching method to conduct classroom teaching must fully take into account the social experience, world outlook and outlook on life of learners, but should also take into account the degree of openness of different communities and cultures. Because the historical, social and political background reasons, the learners' freedom of expression will be subject to certain restrictions. Therefore, the use of literary criticism teaching method in the foreign language classroom teaching will have slightly weaker effectiveness for the students grown up in this environment.

\section{The Specific Application Strategies of Literacy Texts in Foreign Language Teaching}

\section{Help learners to understand the content of literary texts from shallow level to deep understanding}

The understanding for literary texts is composed by both the understanding for the surface meaning and deep understanding of the article. The former refers to the surface information by reading and understanding the contents and words of the article; the latter mainly refers to the in-depth inquiry for the context based on the understanding on the article's content; use questions-asking, dialogue as well as panel discussions and some other ways to understand the intentions expressed by the surface words, and to grasp the author's creative purpose and intentions and so on. Through setting some details which can help learners to understand the article's content, let learners to read text with problems, so that they can have a preliminary understanding for the article. Focus on problem-oriented, not only arrange some overall ideas which help learners to understand the texts, but also design some problems which help to expand background knowledge and visions. In order to better analyze the deeper meaning of literary text; during the teaching process, encourage learners to join in their own point of view, students can also be arranged to comment on the author's point of view. After the analysis of literary texts, use group discussions, story retelling, personal summary and other forms to strengthen students' deep understanding for the literary texts.

Depth Analysis for the Structure of the Literacy Text to Develop Learners' Reading Ability

Foreign language teaching depended on the literary texts involve in the narrative, argumentative, drama and a variety of different genres, among the above literacy texts of the various types of genres, mainly jointly composed by the theme section, description section, transitional section and conclusions sections. In which, the theme section of the summarizes literacy texts are generally appeared in the first paragraph or in the first several paragraphs, and the conclusions sections for the whole article are generally placed in the last paragraph or the last few paragraph. In foreign language teaching, the author will guide learners to analyze how the articles are organized for various genres. For example, the theme of the article is a guidance learning method; the paper has many subjunctives like "Another School Year-What For?" which designed to allow students to understand the purpose of education. Meanwhile, in order to persuade the readers to accept his point of view, often use you or we in the text as a subject for the sentence. Use of effective analysis for literary texts can guide learners to use reasonable reading methods to enhance the effect of learning. 


\section{Discuss Linguistic Phenomenon to Clear Away Obstacles of Foreign Language Teaching}

In literary text teaching, we must attach great importance to the following two linguistic phenomena: Firstly, emphasizes the form coherence of literary texts to understand the vocabulary and grammatical phenomena appeared in the text. To fully understand the vocabulary and grammatical phenomena appeared in the text is to start from the text to read the article, not only to in-depth analysis for the structure of literary texts, but also to explore the use of words and sentences in the text. Therefore, the language is not superpositioned by the chaotic word and sentences, but to show through coherent chapter. Secondly, emphasize the significance coherence of the literary text and to understand the application of the transition words. Transition vocabulary generally used to express the relationships of list, transition, cause and effect, progressive and other relationships. To understand the application of transitions vocabulary in the literary texts through the understanding of the relationships between sentences and sentences, paragraphs and paragraphs, so that it helps to better understand the meaning of the entire article. Besides, in expository or argumentative articles, usually use examples to illustrate the problems or point of views. For example, in the English literary text "Quick Fix Sociey", it demonstrates the theme of literary texts by comparing different scenery and experience in the traveling on motorways and rural roads: the United States has become fast-paced modern society. To prove the fast pace of the USA, the paper also describes numerous examples related to the theme of the articles. The application of transitional words cannot only protect that the literary texts has coherence for the meaning side, and also to help learners to understand the central idea of the text.

\section{Conclusion}

In summary, literacy text teaching can make up for the insufficiency of traditional teaching methods as well as communication methods, and it is an ideal teaching tool for the current foreign language teaching. Literary texts teaching focuses on improving context's impact on semantics, it not only fully pay attention on the form of language, but also helps to develop learners' cultural awareness. Literacy texts teaching can well play the subjective role of the learners, let them get out from a single rigid learning for vocabulary and sentence, discuss the contents, structure and genre of the article from a macro perspective, thus fostering learners' dialectical ability and logical elaborative faculty to help them to learn a foreign language better.

\section{References}

[1] Guohua Yu. On the Literature Teaching under the Constructivism Context in Universities. Journal of Social Science of Jiamusi University, 2007 (6).

[2] Jing Jiang. Rational thinking on the American Literature Integrated into the College English Teaching. Contemporary Education Forum, 2010 (3).

[3] Lita Lv, Ying You. First Teaching Exploration on the Famous Movies Propel American Literature. Journal of Changchun University of Technology, 2010 (5).

[4] Yan Deng. Schema Theory and Literacy Texts Reading Teaching. Journal of Yangtze University, 2011 (6). 